\title{
ReFlecting ON WRITTEN COMMUNICATION AS AN EMBEDdED COMPONENT IN UNDERGRAdUATE ENGINEERING CURRICULA
}

\author{
Arun S. Moorthy and Warren H. Stiver \\ University of Guelph, Guelph, Ontario, Canada \\ [amoorthy,wstiver]@uoguelph.ca
}

\begin{abstract}
Communication in general and technical writing in particular have long been seen as important higher order skills for all graduating and practicing engineers. Developing technical writing skills in our students requires a high level of student-instructor interaction. The interaction needs to provide meaningful, embedded and iterative writing opportunities. Feedback that is detailed and timely is essential for success otherwise numerous writing experiences can reinforce poor writing behaviors. Providing this intensity of interaction can be difficult in a technically focused and packed curriculum. It can be difficult in competition with other time demands on students and instructors alike. In this paper, we present opinions on the challenges, opportunities, and approaches in providing technical writing education and support for undergraduate Engineering students. We focus primarily in the framework of Engineering curricula at Universities in Ontario, but ideas discussed also have applications to higher-level STEM education in general.
\end{abstract}

Keywords: Anecdotal Reflection; Feedback Methods; Technical Writing; Undergraduate Curriculum.

\section{INTRODUCTION}

Effective communication is imperative to professional success. Being able to prepare technical documentation is of particular importance to all graduating and practicing Engineers. Table 1 summarizes technical writing situations for many engineers. Building technical writing skills across these types is a challenge. How do we provide students with meaningful writing experiences and corresponding assessments and valuable feedback?

In this paper, we reflect on our experiences as undergraduate students and the writing development opportunities we were provided. We reflect on the writing experiences offered today to our undergraduate students, and discuss some of the follow-up questions our reflections have fostered. The questions raised are (1) Is collaborative writing the way to promote improved technical writing in a logistically feasible and constructive way? (2) How does reading play into writing? (3) Does frequent writing mean improved writing? (4) Does the feedback we provide optimize students' learning experiences?

Table 1: List of standard technical writing document types. Adapted from [4].

\begin{tabular}{|ll|}
\hline Standard Document Types & \\
\hline Meeting Agendas \& Minutes & Proposals \\
Email, Memos, Letters & Design Reports \\
Documentation & Specifications \\
Hypertext & Patents \\
Style guides & Standards and Codes \\
Websites & Notebooks \\
Literature Review & Investigation Reports \\
Instructions and procedures & Theses \\
Press Releases & Resumes \\
\hline
\end{tabular}

\subsection{Attributes of technical writing}

A quick search on Amazon.ca for 'technical writing' results in hits of over 14000 guides and textbooks. A Google search will yield lecture notes from most Universities across North America. To conduct a comprehensive survey of the entire technical writing literature is beyond the scope of this paper. However, there are a few common and distinct characteristics that many use to qualify writing as technical writing:

1. Pertains to a technical subject: Technical writing must pertain to an objective or critically accessible aspect of a technical subject.

2. Has a purpose: Technical writing is always done for a reason, and this reason is made clear to the reader.

3. Conveys information/facts/data: The information, conclusions and recommendations presented in a technical document are substantiated with facts and/or technical evidence.

4. Concise: Technical documents are limited to essential information. 
5. Directed: Documents are written for a particular reader/audience. The jargon and information is appropriate for that reader.

6. Performed with a particular style and format: Each document type as well developed formats to serve both the author and reader.

A summary list of the aforementioned attributes and their references is provided as Table 2. The noted characteristics are those that have been repeated in multiple instances, but do not reflect all attributes or definitions. Britton [1], for example stated,

"the primary, though certainly not the sole, characteristic of technical and scientific writing lies in the effort of the author to convey one meaning and only one meaning in what he says. That one meaning must be sharp, clear, precise. And the reader must be given no choice of meanings; he must not be allowed to interpret a passage in any way but that intended by the writer. Insofar as the reader may derive more than one meaning from a passage, technical writing is bad; insofar as he can derive only one meaning from the writing, it is good."

We have interpreted Britton's quote to prioritize direction and purpose as the key requirements of technical writing. For the purposes of this reflection, we discuss technical writing in terms of the six stated attributes with equal priority.

The list of technical writing characteristics connects the writer's role in communicating with a reader. One additional, and sometimes separate, aspect of technical writing is its role in helping the writer to develop meaning and understanding for themselves.

In the following sections, we reflect upon our personal technical writing experiences as undergraduate students, the technical writing experiences available to undergraduate Environmental Engineering students at the University of Guelph, and present the questions we continue to ponder.

Table 2: Summary of technical writing characteristics.

\begin{tabular}{|l|l|}
\hline Characteristic & Reference(s) \\
\hline Pertains to technical subject & {$[2][5]$} \\
Purposeful & {$[1][2][4]$} \\
Conveys information/facts/data & {$[2][4]$} \\
Concise & {$[2][4]$} \\
Directed/instructional & {$[1][2][5]$} \\
Maintains standard/particular style and & {$[2][4]$} \\
formatting & \\
\hline
\end{tabular}

CEEA15; Paper 087

McMaster University; May 31 - June 3, 2015

-2 of $6-$

\section{PERSONAL ANECDOTES}

In this section, we present personal anecdotes reflecting upon our experiences as undergraduate Engineering students at McMaster University and the University of Toronto, respectively, and as instructors (teaching assistant and professor) at the University of Guelph. These are opinions built upon memories rather than formal notes, and so we highlight that these passages should not be taken as absolute fact. There may have just as easily been additional writing assessments which we fail to recall, or opportunities for feedback of which we are/were personally unaware. These anecdotes frame our discussion that follows.

\subsection{Arun and Warren as students}

Arun Moorthy, Chemical and Bioengineering (05-10), McMaster University

In general, Arun's memory is quite fuzzy. In particular, limited memory of writing details in first three years of engineering. Arun recalls having fairly significant individual writing components in the following courses:

- 2nd year: Engineering Communication

- 4th year: Chemical Engineering Labs, Biochemistry/Bioengineering Labs, Engineering Ethics, Chem. Eng. in Medicine, Industrial Chemistry

- 5th year: Capstone Project, Wastewater Treatment Design, Sustainable Development

Engineering Communication provided many opportunities to write, the most memorable of which was a literature review to end the course. An interesting aspect of the literature review was that it preceded by a presentation. Arun believes this was done so students could be confident about their report content prior to submitting the final document. Unfortunately he has no recollection of the type of feedback provided.

Upper-year reports were primarily assessed for result accuracy/precision and not with particular emphasis on writing/communication. The one exception was his Industrial Chemistry class, where students participated in an iterative review process. Reports were first reviewed by a peer in the class (where students were assigned a grade for the quality of their peer-review for a classmates paper), followed by the TA, and finally by the course instructor.

The capstone project was assessed continuously as sections were completed and submitted. This provided for a fairly thorough evaluation of technical content and 
writing quality, as well as other aspect of report construction (figures, schematics, formatting, etc).

\section{Warren Stiver, Chemical Engineering (78-82), University of Toronto}

Warren's memory may be fuzzier given the time span. The writing experiences recalled are:

- $\quad$ 1st year: one project report, one complimentary studies course with essays

- 2nd year: project report, many brief (same day or next day) structured laboratory reports

- 3rd year: one lab course with one formal laboratory report and multiple written abstracts

- 4th year: one design report, one thesis

The writing assignments in third and fourth year were the only ones that represented a significant grade in their respective courses. The third-year lab course proved to be the most memorable. The lab was a large pilot scale lab that took the better part of the day to setup, run and generated a considerable data set. Over the course of the term each team ran multiple of these labs with one member assigned to write the formal report and the others required to submit an abstract. The formal report was expected to include a thorough analysis of the results and act as a complete documentation of the work done. A formal laboratory report guideline was provided to the students. One Full Professor reviewed and graded all submitted reports. The feedback Warren received for his initial submission was his first experience with volumes of critical feedback (and the red ink associated with it). Part of the feedback process included a chat with the reviewing Professor. Warren didn't recall this being very effective as he was overwhelmed with the amount of red ink. His final report underwent two rewrites prior to final grading; and these were the days before word processing. The criticism really hit home owing to Warren's respect for the reviewing professor. The iterative submissionfeedback process helped Warren recognize his writing was a substantive weakness. He is not sure that he necessarily 'improved' through the process, as most of the rewriting felt a bit like guessing. Nor did he feel like there was substantial improvement in his writing through the remainder of his undergraduate program. However, this experience really made him aware that he had work to do to become a competent writer.

All of the writing was as an individual. Even the team final design report was strictly written along lines of labour division as encouraged by the course to permit individual grading.

\subsection{Brief Survey of Environmental Engineering at University of Guelph}

Environmental Engineering undergraduate students at the University of Guelph take 24 common environmental engineering courses (with course prefix ENGG in the undergraduate course calendar). A portion of these courses is shared with some or all other engineering programs and some are specific to the Environmental Engineering program. A specific course dedicated to technical writing is not a requirement in their program.

Technical writing is embedded throughout the program. Only the third year design course (Engineering $\&$ Design III) has a specific emphasis on writing. Of the 24 common courses, 19 include writing assessments, totaling 61 writing assignments in all. Nearly $25 \%$ of a student's overall grade in these 24 courses is associated with writing based assessments.

The students write 39 lab reports across twelve of the courses. The weighting of each lab report ranges from a low of $1.5 \%$ each to a high of $25 \%$. The median weighting is in the $4-5 \%$ range. Students write 3 design proposals and write 11 design reports (interim and final). The design reports ranged from 15 to $30 \%$ in terms of course weighting. The remaining 9 writing assessments include memos, literature reviews and others.

Overall the writing is extensive and embedded across many courses. Five of the 18 document types listed in Table 1 are assessed. The assessed writing heavily emphasizes lab reports and design reports. Some of the other writing types are active. Students are writing and sending emails, they are creating meeting agendas and writing meeting minutes and they certainly have an active resume. However, these elements are not assessed within their courses. The remaining ten types are not apparent in the curriculum.

The overwhelming majority of the writing is in teams with team sizes ranging from 2 to 5 . Only 2 of their 61 documents are individual submissions.

Overall, the writing in the environmental engineering curriculum appears extensive. It reflects a common perspective among faculty that writing is important. However, the writing is not coordinated. Faculty are only lightly aware of the extent of writing in other courses and the nature of expectations and assessment conducted.

\section{ENGG*2560 - Environmental Engineering Systems}

Environmental Engineering systems is a required course for students studying Environmental Engineering or Water Resource Engineering at the University of Guelph. Warren has served as the professor for the last eight years and Arun has served as one of the teaching assistants for the past three years. Students are introduced to fundamental concepts of mass conservation, chemical 
reactions and equilibrium relationships, and its application to environmental systems. In addition, students are introduced to the basics of noise measurements and modeling techniques. Students are assessed by a combination of tests $(20 \%)$, an exam (30\%), and three major lab reports $(10,25$ and $15 \%)$. The lab reports are written in pairs. Students are given an outline of basic formatting and report structure and a corresponding rubric. Students are given flexibility in terms of how to present, analyse and discuss their results in the context of stated objectives. The three reports work from the same guidelines and assessment rubric. So feedback and experience benefits preparation their subsequent reports in the course.

The first and third reports are assessed by course TAs, and the course instructor evaluates the second report. Feedback is provided in the form of a detailed evaluation rubric with significant space for additional commentary. The rubric is structured to align with the expected structure of the report and does not have an explicit row dedicated to communication. The feedback for each section reflects whether that section met its objectives. The overall grade is not based on a formula weighting of each section of the rubric. Instead it is weighted based on a judgment of the strengths and weaknesses of each section in addition to the overall effectiveness. Students are told that their results and discussion's ability to build and defend interpretations, conclusions and recommendations will carry the heaviest weight. It is pointed out to them that success at this level relies on a well-run experiment and effective data analysis. An excellent report requires the correct conceptual understanding and technical merit of their written arguments.

We have found that the quality of the first report is varies greatly between teams. Some teams catch on to the argument formulation expectation while others struggle with the analytical process. The first report helps to prepare the students for the larger and deeper expectations of the second report. The quality of the third report is generally better both in terms of assigned grades and in terms of overview perspective of the teaching assistants.

\section{DISCUSSION}

This paper began as an informal discussion amongst ourselves about the quality of technical writing we were seeing by our students, about the quality and evolution of our own technical writing, and our opinions about how to create/ensure improvement in both. These discussions led to significant personal reflection. These discussions led us to read and re-read the published opinions of others. And mainly, these discussions led to more questions. Here we share some of our key talking-points or open-ended questions, as well as some of our preliminary opinions.
Is collaborative writing a way to promote improved technical writing in a logistically feasible and constructive way?

Collaborative writing is an important activity for Engineers. Nelson [3] highlights that collaborative writing is what will be expected of graduating students upon entering the workplace. During the process of preparing reports, collaborators should debate their objectives, deliberate their results, and challenge each other to present ideas in the most comprehensible manner.

Collaborative writing can permit increased depth and/or offer less work. The increased depth associated with increased expectation of technical analysis with a corresponding increase in technical writing insight. The time reduction is associated with shared student workload in the analysis and writing, and fewer reports to assess for the instructors.

An issue with collaborative writing, particularly at the undergraduate level, is ensuring a positive learning experience for all group members. In a scenario where two students are actively engaged in all project tasks, one would have a very good argument that collaborative work fosters peer-peer discussions that are beneficial to the students' development. Feedback is within minutes or hours and easily iterative. It is tough to imagine instructor feedback at this pace. The instructor feedback following this rapid peer-peer decision process serves to judge their actively debated positions.

In the case where there is one active member and the remaining members are passive then it is difficult to argue that the active member gains much from the collaboration. If the scope of the project was expanded to reflect team size then the active members face a daunting challenge. The passive members gain a grade but it is tough to argue that they learn anything without engaging.

In the case of a strict division of labour the collaborative model is less effective as well. The workload is lessened but the quality of peer-peer feedback is severely diminished. The instructor feedback on the various elements of the work is valuable only to the member that led that element.

Collaborative writing can provide valuable, essential and rapid feedback. However, it fails to add value when students opt not to engage. And so the unresolved question is, how to frame collaborative writing to ensure active contributions to the entire report by all team members.

\section{How does technical reading play into technical writing?}

It is widely understood that reading and lots of it is essential to the development of effective writing skills. Is this true for technical writing? Common sense might suggest technical reading, and the breadth of technical 
material, is essential to developing technical writing skills. However, reflecting on our individual undergraduate experiences resulted in very little memory of substantial reading requirements. Our reading primarily consisted of textbook chapters, lab instructions, and a few journal articles. The current undergraduate students seem to have little assigned technical reading and little evidence of breadth in that reading. They still read some textbook chapters, instructional material and some journal articles. They are well versed in quick reading associated with the Internet and social media. In first year, they are required to read at least one patent. They write eleven design reports but never read a professional one throughout their program. Is this reading amount, level and breadth sufficient?

\section{Does frequent technical writing result in improved technical writing?}

In Environmental Engineering Systems students produce three substantial reports over the course of the semester. Feedback is thorough and detailed. Students had time (2-3 weeks) to digest the feedback from the first report before submission of the second report. Return of the second reports aligned with the submission of the third report. So we wonder, how much of the observed improvement in the third report was due to the depth of feedback we provide versus the improvement due to familiarity and comfort with report writing expectations in this course.

At the same time, the Environmental Engineering Systems students are taking two other courses requiring lab reports. In these two courses, they write 8 reports, worth $4-5 \%$ each. Is the progression of the students writing skills through the semester a result of this writing frequency?

An extension to this question leads to whether the 61 writing assessments for Environmental Engineering students are effectively building technical writing skills? Currently these assessments are at best lightly coordinated. Do the 61 build to effective technical writers? Do they foster critical thinking and critical argument building capacity?

\section{Does the feedback we provide optimize students' learning experiences?}

Feedback mechanisms, particularly efficient feedback mechanisms, are of great importance to us as instructors. We want to provide authentic assessment that help students learn. Our students only have so many hours in the day. We also only have so many hours in the day to review. Our discussions led us to ponder what types of feedback are useful, whether there is an optimal amount of feedback, and how we can implement these systems efficiently.

Stern and Solomon [6] reviewed the types of feedback faculty were providing to writing assignments. They found the overwhelming amount of feedback was of the technical corrections-type (spelling/grammar), with very few criticisms of the content-type (argument formulation/organization). They suggest that this lack of critical feedback may limit the level of improvement students see of their work.

In the spirit of optimizing writing experiences, it would be valuable for the curriculum to be coordinated. Some writing should be focused on writing mechanics (spelling, grammar and macroscopic format compliance). It is essential that some writing expect more intensive argument formulation. A curriculum should coordinate and understand these roles to most efficiently use its time resources. The writing mechanics foundation should be fully established in the early years and probably fits with mostly shorter documents. Starting in first year, writing that requires argument building is essential. Critical writing should strategically continue throughout all four years. The depth and complexity of this writing should advance in sequence with advancing technical depth and complexity. It is essential that these written works be assessed for more than writing mechanics.

In grading reports for Environmental Engineering Systems, it was very rare that we'd find a report with welldeveloped arguments and insights in a paper riddled with grammatical mishaps. Similarly, a "well-written" report with incoherent analysis was a rare combination. However, technically correct analysis is not sufficient for technically proficient writing. Effective technical writing requires another level of understanding to be successful. Pushing students to write effectively can be important means to advance technical competency.

Much like it is difficult to judge a students understanding of physical phenomena when their basic algebra is weak, judging quality of arguments while basic writing skills are lacking might in fact be unachievable. The way we grade assignment problems with algebra mistakes is we use our discretion to interpret what the student meant to execute. This is how we overcome poor writing as well, providing feedback for what our experiences and discretion believe the student meant to communicate.

If when we assess our students writing we guess at whether they understand the concepts in spite of what they wrote then we may be the wrong assessors. Britton stated [1]

"in all too many instances, at least in college, the student writes the wrong thing, for the wrong reason, to the wrong person, who evaluates it on the wrong basis." 
One could argue that the statement of Britton still holds 50 years later. Can an expert effectively judged whether technical writing is providing a persuasive argument when they start with a position of agreement or understanding?

In these cases, the collaborative writing may be the more effective and critical judge than the professor or TA. The peer must be convinced of the argument because they are not certain a priori.

A feedback mechanism that we discussed previously was the intrinsic commentary students receive from their peers during collaborative work. As peers are often on level playing fields, we wonder if a system where students write for each other rather than for a teacher, and for comments rather than a grade, is something we can accomplish? There would still have to be instructor involvement and eventually the assignment of grades, but if we can move the culture of student writing from "a novice communicating to an expert" to "a colleague communicating with other colleagues", it is possible that students enjoy a more complete, and realistic, writing experience.

\section{CONCLUSIONS}

In actively reflecting and discussing technical writing we were able to realize that the challenges in providing technical writing support to undergraduate students, particularly with the focus of preparing future Engineers, are more diverse than what they may initially appear. Because we teach core skills (theory, design) and higherorder skills (communication) from the position of "expert", the feedback we are able to provide may not be genuinely representative of a students writing ability. We hypothesize that an ideal support system would center around frequent collaborative writing assignments with equally engaged/active students who can support and challenge each other. This collaboration between students would also be supplemented with structured and regular feedback from an instructor to help assure student development is progressing in the correct direction.

We believe that a more coordinated curriculum within an embedded strategy is appropriate. Specific and strategic reading is a missing element. Finally, writing experiences that hit more writing types would be appropriate. Attempting to write a patent, a new standard or an instruction manual might offer more value than one of the 39 lab reports.

\section{References}

[1] W.E Britton. "What is Technical Writing", College Composition and Communication, National Council of Teachers of English, 1965, 16(2), pp 113-116.

[2] K.G. Budinski. Engineers' guide to technical writing. ASM International, 2001.

[3] S. Nelson. "Engineering and Technology Student Perceptions of Collaborative Writing Practices”, IEEE Transactions on Professional Communication, 2003, 46(4), pp 265-276.

[4] L. Perelman and E. Barrett. The Mayfield handbook of technical and scientific writing. McGraw-Hill, Inc., 1997.

[5] Society for Technical Communication."Defining Technical Communication.” Retrieved April 14, 2015.

[http://www.stc.org/about-stc/the-profession-all-abouttechnical-communication/defining-tc]

[6] L.A. Stern and A. Solomon. "Effective faculty feedback: The road less traveled”, Assessing Writing, 2006, 11, pp 22-41 